\section{OPEN VERSUS \\ ENDOVASCULAR REPAIR FOR \\ ACUTE TRAUMATIC \\ THORACIC AORTIC RUPTURE}

To the Editor:

In the November issue of the Journal, Canaud and colleagues ${ }^{1}$ wrote to compare 2 methods of acute traumatic aortic rupture repair. Comparison of these techniques is very instructive; however, their decision to abandon the traditional open technique and their recommendation to use endovascular stenting as a first-line approach are discordant with and irrelevant to the results obtained by the authors.

Despite an identical injury severity score for the 2 groups, a substantial selection bias resulted from the inclusion of 3 patients with free aortic ruptures, exclusively in the surgical group. This almost unsalvageable condition has been responsible for 3 operative deaths and for 3 of 4 inhospital deaths reported with the open technique. Interestingly enough, statistical analysis failed to disclose any difference in in-hospital mortality between the 2 groups. The exclusion of these 3 moribund patients for a more objective comparison would have reset the in-hospital mortality in the open group to $3.1 \%$ ( 1 of 32 patients). In addition, no cases of paraplegia were reported. For obscure reasons, these outstanding results obtained with the traditional open technique were not emphasized by Canaud and colleagues, ${ }^{1}$ leaving the reader under the impression of a

\footnotetext{
The Editor welcomes submissions for possible publication in the Letters to the Editor section that consist of commentary on an article published in the Journal or other relevant issues. Authors should: - Include no more than 500 words of text, three authors, and five references. - Type with double-spacing - See http://jtcs.ctsnetjournals.org/misc/ifora.shtml for detailed submission instructions. - Submit the letter electronically via jtcvs.editorialmanager.com. Letters commenting on an article published in the JTCVS will be considered if they are received within 6 weeks of the time the article was published. Authors of the article being commented on will be given an opportunity of offer a timely response ( 2 weeks) to the letter. Authors of letters will be notified that the letter has been received. Unpublished letters cannot be returned.
}

sudden stampede for a new uncertain technology without clear arguments to support this change.

This typically younger patient population deserves a safe, durable, and definitive aortic repair. ${ }^{2}$ As Canaud and colleagues $^{1}$ agree, these 2 goals can only be reached in an experienced center. Other authors who have used a highly standardized open surgical technique have published similar excellent results. Bouchard and associates, ${ }^{3}$ in a series of 97 patients protected with a partial right heart bypass, reported a $4 \%$ in-hospital mortality and no cases of paraplegia. In my own experience $^{4}$ of 114 consecutive patients with an acute traumatic rupture of the descending thoracic aorta (median injury severity score of 42.5 ), the inhospital mortality was $3.5 \%$ (4 of 114 cases), and no ischemic spinal cord deficits occurred in the 110 patients who reached the operating room with an intact spinal cord. Similarly to the series of Canaud and colleagues, ${ }^{1}$ all these patients were protected with a partial left heart bypass with either minimal or no systemic heparinization.

A suspected lack of standardization of the technique of operative repair in many series has resulted in a variability of surgical results, opening the way to endovascular grafting. When analyzing the results reported by Canaud and colleagues, ${ }^{1}$ this argument does not apply to their group. For this reason, I personally have great difficulty in understanding their thought processes in taking this sudden new turn and recommending the use of stentgrafting as a first-line approach. This appears to me to completely contradict the conclusions published by the same authors ${ }^{5}$ in another article found in the same issue of this Journal, "Surgical conversion after thoracic endovascular aortic repair."

Alain Verdant, $M D$ Department of Thoracic and Vascular Surgery Hôpital du Sacré Coeur Montréal, Quebec, Canada

\section{References}

1. Canaud L, Alric P, Branchereau P, Joyeux F, Hireche K, Berthet JP, et al. Open versus endovascular repair for patients with acute traumatic rupture of the thoracic aorta. $J$ Thorac Cardiovasc Surg. 2011;142:1032-7.

2. Verdant A. Endovascular management of traumatic aortic injuries. Can J Surg. 2006;49:217; author reply $217-8$.

3. Bouchard F, Bessou JP, Tabley A, Litzler PY, HaasHubscher C, Redonnet M, et al. Ruptures traumatiques aiguës de l'aorte thoracique et de ses branches. Résultats du traitement chirurgical. Ann Chir. 2011;126:201-11. French.

4. Verdant A. Contemporary results of standard open repair of acute traumatic rupture of the thoracic aorta. J Vasc Surg. 2010;51:294-8.

5. Canaud L, Alric P, Gandet T, Albat B, MartyAné C, Berthet JP, et al. Surgical conversion after thoracic endovascular aortic repair. J Thorac Cardiovasc Surg. 2011;142:1027-31.

doi:10.1016/j.jtcvs.2012.01.058

\section{Reply to the Editor:}

We appreciate Verdant's comments regarding our recent work, "Open versus endovascular repair for patients with acute traumatic rupture of the thoracic aorta" ${ }^{1}$; however, we dispute his assertion that we claimed that open repair should be abandoned. Our experience did demonstrate that endovascular repair is associated with both a lower rate of morbidity and a lower mortality. Our results are concordant with the results of the prospective multicenter study of the American Association for the Surgery of Trauma, ${ }^{2}$ which concluded that endovascular repair is associated with significantly lower mortality and fewer blood transfusions.

The results of our study thus have prompted us to consider endovascular repair as the first-line therapy for acute traumatic rupture of the thoracic aorta. For patients in hemodynamically unstable condition, endovascular repair should be considered first. For patients in hemodynamically stable condition, however, we believe that the preoperative morphologic evaluations should aim to assess aortic anatomy and thereby detect possible technical limitations (aortic diameter $<20 \mathrm{~mm}$, severe aortic isthmus angulation, short proximal aortic neck 
$<20 \mathrm{~mm}$, conical aorta). In the presence of any of these technical restrictions, open surgical treatment should be considered to avoid major preoperative or postoperative complications related to endovascular repair, such as stent-graft collapse or inadvertent coverage of the supra-aortic trunks.

The selection bias reported by Verdant with respect to the number of free ruptures in our study is wrong. Actually, a free rupture was observed in 5 patients in the open repair group and in 4 patients in the endovascular repair group.

The conclusion of our other work in the same issue of the Journal, "Surgical conversion after thoracic endovascular aortic repair," 3 noted that complications may occur after thoracic endovascular aortic repair, either as a result of device failure or from other adverse events, and we stated that these events may necessitate conversion to open repair. Open conversion can be performed with encouraging results by a team experienced in the management of diseases of the thoracic aorta. With the increasing use of thoracic endovascular aortic repair, more and more patients will be seen with indications for surgical conversion. This article's conclusion does not appear to us to be in complete contradiction with our study of the repair of traumatic transection of the thoracic aorta.

\section{Ludovic Canaud, $M D$ \\ Pierre Alric, $M D, P h D$ \\ Department of Thoracic and \\ Vascular Surgery \\ Arnaud de Villeneuve Hospital \\ Montpellier, France}

\footnotetext{
References

1. Canaud L, Alric P, Branchereau P, Joyeux F, Hireche K, Berthet JP, et al. Open versus endovascular repair for patients with acute traumatic rupture of the thoracic aorta. $J$ Thorac Cardiovasc Surg. 2011;142:1032-7.

2. Demetriades D, Velmahos GC, Scalea TM, Jurkovich GJ, Karmy-Jones R, Teixeira PG, et al. Operative repair or endovascular stent-graft in blunt traumatic thoracic aortic injuries: results of an American Association for the Surgery of Trauma Multicenter Study. J Trauma. 2008;64:561-71.
}

3. Canaud L, Alric P, Gandet T, Albat B, MartyAné C, Berthet JP. Surgical conversion after thoracic endovascular aortic repair. J Thorac Cardiovasc Surg. 2011;142:1027-31.

doi:10.1016/j.jtcvs.2012.01.059

\section{DOES ANASTOMOSIS DEVICE OR EPIAORTIC}

ULTRASONOGRAPHY REDUCE THE RISK OF POSTOPERATIVE STROKE AFTER CORONARY ARTERY BYPASS GRAFTING?

\section{To the Editor:}

I read with interest the recent study by Emmert and colleagues ${ }^{1}$ on the beneficial effects of off-pump coronary artery bypass grafting (OPCAB). I share with them their enthusiasm regarding $\mathrm{OPCAB}$ and strongly believe in its benefits. Emmert and colleagues ${ }^{1}$ showed that OPCAB is associated with a significantly lower risk of postoperative stroke, as also shown in a number of previous studies. They stated that this difference may be mainly related to the use of the HEARTSTRING anastomosis device (MAQUET Cardiovascular LLC, San Jose, Calif), because the rate of stroke with this method $(0.7 \%)$ was similar to that among patients who underwent $\mathrm{OPCAB}$ with total arterial revascularization without the need for proximal anastomosis $(0.8 \%)$. In contrast, patients who underwent OP$\mathrm{CAB}$ with partial clamping had a stroke rate of $2.3 \%$, similar to those who underwent conventional coronary artery bypass grafting $(2.4 \%)$. Emmert and colleagues ${ }^{1}$ suggested that the use of the HEARTSTRING anastomosis device was the main determinant of improved results during OPCAB. Although this could be true, they failed to investigate the main determinant of postoperative stroke itself. In fact, even if the mechanisms leading to postoperative cerebrovascular events after cardiac surgery are multifactorial, ${ }^{2}$ atherosclerosis of the ascending aorta is certainly the most powerful risk factor. ${ }^{3}$ Emmert and colleagues ${ }^{1}$ did not use epiaortic ultrasonography to evaluate the status of the ascending aorta in these cases. Thus a number of their patients with severe atherosclerosis of the ascending aorta, involving the lateral or anterior walls of the aorta, ${ }^{3}$ or stage III disease, ${ }^{4}$ were probably exposed to cerebral embolism after either aortic crossclamping or partial cross clamping. We have previously observed in our institutional series that postoperative stroke rate was significantly lower when the operation was performed by OPCAB surgeons who routinely used epiaortic ultrasonographic scanning for planning the revascularization strategy than with conventional coronary artery bypass grafting surgeons did not use epiaortic ultrasonographic scanning $(0.4 \%$ vs $3.9 \% ; P=.015){ }^{5}$ Because a recent meta-analysis showed that pooled rate of immediate postoperative stroke after OPCAB with the use of the HEARTSTRING device was $1.9 \% \quad(95 \%$ confidence interval, $0.8 \%-4.5 \%$ ), it seems reasonable to consider the status of the ascending aorta to be the most important determinant of postoperative stroke. The potential clinical benefits and costs of using the HEARTSTRING device during OPCAB should be investigated in patients with stage III ascending aortic disease, as graded by intraoperative epiaortic ultrasonography, because the use of aortic partial clamping in these patients is not safe. The use of the HEARTSTRING device is probably not appropriate in patients with no disease (stage I) or mild disease (stage II) of the ascending aorta.

\section{Fausto Biancari, $M D, P h D$ Department of Surgery Oulu University Hospital Oulu, Finland}

\section{References}

1. Emmert MY, Seifert B, Wilhelm M, Grünenfelder J, Falk V, Salzberg SP. Aortic no-touch technique makes the difference in off-pump coronary artery bypass grafting. J Thorac Cardiovasc Surg. 2011; 142:1499-506.

2. Biancari F, Myllylä M, Porela P, Laitio T, Kuttila K, Satta J, et al. Postoperative stroke in patients on ora anticoagulation undergoing coronary artery bypass surgery. Scand Cardiovasc J. 2011;45:360-8.

3. van der Linden J, Hadjinikolaou L, Bergman P, Lindblom D. Postoperative stroke in cardiac 